\title{
Associations between post-stroke motor and cognitive function: a cross-sectional study
}

Marte Stine Einstad ${ }^{1 *}$, Ingvild Saltvedt ${ }^{1,2}$, Stian Lydersen ${ }^{3}$, Marie H. Ursin ${ }^{4}$, Ragnhild Munthe-Kaas ${ }^{4}$, Hege Ihle-Hansen ${ }^{5}$, Anne-Brita Knapskog ${ }^{5}$, Torunn Askim', Mona K. Beyer ${ }^{6,7}$, Halvor Næss ${ }^{8,9,10}$, Yngve M. Seljeseth ${ }^{11}$, Hanne Ellekjær ${ }^{1,12}$ and Pernille Thingstad ${ }^{1}$

\begin{abstract}
Background: Motor and cognitive impairments are frequently observed following stroke, but are often managed as distinct entities, and there is little evidence regarding how they are related. The aim of this study was to describe the prevalence of concurrent motor and cognitive impairments 3 months after stroke and to examine how motor performance was associated with memory, executive function and global cognition.

Methods: The Norwegian Cognitive Impairment After Stroke (Nor-COAST) study is a prospective multicentre cohort study including patients hospitalized with acute stroke between May 2015 and March 2017. The National Institutes of Health Stroke Scale (NIHSS) was used to measure stroke severity at admission. Level of disability was assessed by the Modified Rankin Scale (mRS). Motor and cognitive functions were assessed 3 months post-stroke using the Montreal Cognitive Assessment (MoCA), Trail Making Test Part B (TMT-B), 10-Word List Recall (10WLR), Short Physical Performance Battery (SPPB), dual-task cost (DTC) and grip strength (Jamar ${ }^{\circledR}$ ). Cut-offs were set according to current recommendations. Associations were examined using linear regression with cognitive tests as dependent variables and motor domains as covariates, adjusted for age, sex, education and stroke severity.
\end{abstract}

Results: Of 567 participants included, 242 (43\%) were women, mean (SD) age was 72.2 (11.7) years, 416 (75\%) had an NIHSS score $\leq 4$ and $475(84 \%)$ had an mRS score of $\leq 2$. Prevalence of concurrent motor and cognitive impairment ranged from $9.5 \%$ for DTC and 10WLR to $22.9 \%$ for grip strength and TMT-B. SPPB was associated with MoCA (regression coefficient $B=0.465,95 \% \mathrm{Cl}[0.352,0.578]$ ), TMT-B $(B=-9.494,95 \% \mathrm{Cl}[-11.726,-7.925]$ ) and 10WLR $(B=0.132,95 \% C l[0.054,0.211])$. Grip strength was associated with MoCA $(B=0.075,95 \% C l[0.039,0.112])$, TMT-B $(B=-1.972,95 \% C l[-2.672,-1.272])$ and 10WLR $(B=0.041,95 \% C l[0.016,0.066])$. Higher DTC was associated with more time needed to complete TMT-B $(B=0.475,95 \% \mathrm{Cl}[0.075,0.875])$ but not with MoCA or 10WLR.

\footnotetext{
* Correspondence: marte.s.einstad@ntnu.no

'Department of Neuromedicine and Movement Science, Faculty of Medicine and Health Sciences, NTNU-Norwegian University of Science and Technology, Trondheim, Norway

Full list of author information is available at the end of the article
}

(c) The Author(s). 2021 Open Access This article is licensed under a Creative Commons Attribution 4.0 International License, which permits use, sharing, adaptation, distribution and reproduction in any medium or format, as long as you give appropriate credit to the original author(s) and the source, provide a link to the Creative Commons licence, and indicate if changes were made. The images or other third party material in this article are included in the article's Creative Commons licence, unless indicated otherwise in a credit line to the material. If material is not included in the article's Creative Commons licence and your intended use is not permitted by statutory regulation or exceeds the permitted use, you will need to obtain permission directly from the copyright holder. To view a copy of this licence, visit http://creativecommons.org/licenses/by/4.0/ The Creative Commons Public Domain Dedication waiver (http://creativecommons.org/publicdomain/zero/1.0/) applies to the data made available in this article, unless otherwise stated in a credit line to the data. 
(Continued from previous page)

Conclusion: Three months after suffering mainly minor strokes, 30-40\% of participants had motor or cognitive impairments, while $20 \%$ had concurrent impairments. Motor performance was associated with memory, executive function and global cognition. The identification of concurrent impairments could be relevant for preventing functional decline.

Trial registration: ClinicalTrials.gov Identifier: NCT02650531.

Keywords: Stroke, Cognitive function, Motor function, Function

\section{Background}

Stroke is reported to be the third-most common cause of disability-adjusted life years (DALYs) worldwide [1]. Post-stroke motor and cognitive impairments are prevalent, and even though function improve during the first 3 months after stroke [2], approximately one fifth of stroke patients experience stroke-related disability 3 months post-stroke [3], highlighting the need of early detection and prevention of further deterioration of function. Motor deficits leading to impaired gait, balance and general reduction in physical function are seen in almost $50 \%$ of stroke cases 3 months after stroke [4]. The prevalence of mild and major cognitive impairments appears to vary from 14 to $29 \%$ and 11 to $42 \%$, respectively, 3 months post-stroke, depending on the method used to define post-stroke neurocognitive disorder [5]. In a study assessing stroke patients 3-6 months poststroke, Sachdev et al. reported a prevalence of mild cognitive impairment and dementia of 37 and $21 \%$, respectively [6], underlining the importance of addressing cognitive impairments following stroke.

Assessments of motor and cognitive functions have established roles in the follow-up of stroke patients but have traditionally been studied, diagnosed and managed as distinct entities [7]. However, the stroke lesion itself, comorbid cerebrovascular disease and neurodegeneration may all cause both cognitive and motor impairments [8].

It is well-documented that older people in the general population with concurrent impairments in motor and cognitive functions are at increased risk of developing dementia as well as being at risk for higher rates of hospital admissions, falls, dependency and mortality [7, 9, 10]. In population-based studies, the simultaneous presence of gait disturbances and memory complaints, called motoric cognitive risk (MCR) syndrome, has also been shown to increase risk of developing dementia [10]. Additionally, in the stroke population, impaired balance and gait post-stroke are significant risk factors for cognitive impairment $[11,12]$. However, previous studies are few in number, and there is a need for additional knowledge about the relationship between motor and cognitive impairments based on multicentre studies of stroke populations.
Previous research has clearly indicated an association between cognitive and motor performance among older people. Vascular pathology appears to be related to motor impairments and executive dysfunction, while impaired memory is a typical symptom of neurodegeneration, especially Alzheimer's disease [13, 14]. Gait performance following stroke has been reported to be associated with global cognition, executive function and memory $[11,12,15]$. The inability to combine a cognitive task with a motor task like walking, assessed as dual-task cost, has been proposed as an early marker of dementia development [16]. However, studies of associations between motor function and different cognitive domains in older populations have found divergent results $[10,17-20]$, and there is little evidence in stroke populations. We hypothesized that motor performance would be more closely related to executive function than to memory in a stroke sample, reflecting vascular pathology. A recent consensus report recommended a minimum core battery for assessing the motor-cognitive interphase related to ageing and neurodegeneration in order to increase comparability across research studies, detect subtle or common reversible factors, and accelerate research on dementia, falls, and ageing-related disabilities [7]. This test battery included gait speed, dualtask cost of gait speed (DTC-speed), the Montreal Cognitive Assessment (MoCA) and the Trail Making Test Parts A \& B (TMT-A \& -B) [21-23].

The overall aim of this study was to describe concurrent impairment in cognition and motor performance and to explore how motor performance was related to global cognition, executive function and memory 3 months post-stroke.

\section{Methods \\ The Nor-COAST study}

The Norwegian Cognitive Impairment After Stroke (Nor-COAST) study is a prospective cohort study with participants recruited from five different hospitals in Norway between May 2015 and March 2017. The details of the study have been published elsewhere [24]. Inclusion criteria were as follows: a diagnosis of stroke according to the WHO criteria [25] or findings on magnetic resonance imaging (MRI) compatible with 
intracerebral haemorrhage or infarction; symptom onset within 1 week of admission; age $>18$ years; the ability to communicate in Norwegian; and residing within the catchment area of the participating hospitals. Patients with expected survival $<3$ months were excluded. The present study is a cross-sectional sub-study of the NorCOAST study, utilizing data from the three-month follow-up. In addition to the inclusion and exclusion criteria for the Nor-COAST, the participants included in the present study had to have completed at least one cognitive and one motor assessment at three-month follow-up.

\section{Assessments}

\section{Participant characteristics}

The National Institutes of Health Stroke Scale (NIHSS) [26] score at admission was used to measure stroke severity; possible scores range $0-42$, with a higher score indicating a more severe stroke. Mild stroke was defined as NIHSS score 0-4 points, for moderate stroke 5-12 points, for moderate to severe stroke $16-20$ points and for severe stroke $>20$ points [4]. At three-moth followup, instrumental activities of daily living (IADL) were assessed with the Nottingham Extended Activities of Daily Living (NEADL), a 0-66-point scale where a higher score indicates greater independence [27], and the inability to walk $200 \mathrm{~m}$ was used as an indicator of physical frailty. Both assessments were based on information collected through interview of patient or caregiver. Functional dependency was measured with the Modified Rankin Scale (mRS) [28], which comprises six levels scored as $0-5$ where 0 indicates no disability and 5 indicates severe disability; 6 is used to indicate death. Prestroke score on mRS was recorded at baseline though interview of caregivers, while status at 3 months was assessed by interview of patient or caregiver at the hospital outpatient clinic. The Charlson Comorbidity Index [29] was used as a descriptive measure to quantify comorbidity among the participants and was based on participant information and medical records collected at baseline.

\section{Motor performance tests}

The Short Physical Performance Battery (SPPB), an assessment of mobility, consists of three tasks: gait speed, assessed by $4-\mathrm{m}$ timed trials; balance, assessed by the ability to stand for $10 \mathrm{~s}$ with the feet in three different positions; and leg strength, measured by the time required for five sit-to-stand movements from a chair. Each task is scored on a 4-point scale, with a total score ranging $0-12$ and higher scores indicating better function [30]. The cut-off for a score indicating impairment was set at $<10$ points [31]. To assess dual-task cost, the participants were first asked to walk $10 \mathrm{~m}$ at their preferred gait speed, and then walk the same distance while counting backwards [21]. Dual-task cost was calculated using the formula ([single-task gait speed - dualtask gait speed]/single-task gait speed $\times 100=$ dual-task cost) [16]; a reduction of more than $20 \%$ was characterized as impairment [16]. Grip strength was measured with a Jamar Hydraulic Hand Dynamometer (Lafayette Instrument Europe, Loughborough, UK), and the highest score of three attempts using the stronger hand was applied in the analyses. Scores $<21 \mathrm{~kg}$ were characterized as impairment for women and $<37 \mathrm{~kg}$ for men [32].

\section{Cognitive assessments}

Global cognition was assessed with the Montreal Cognitive Assessment (MoCA) with possible scores ranging from 0 to 30 and higher scores indicating better cognition [23]. A cut-off for impairment was set at $<24$ points, based on previous recommendations [33]. To assess executive function, the Trail Making Test Part B (TMT-B) [22] was applied. Taking more than $167 \mathrm{~s}$ (one standard deviation $[\mathrm{SD}]$ below normative mean for the age group 75-77 years) [34] to complete the test was defined as executive dysfunction. The 10-Word List Recall (10WLR), part of the 10-Word List Learning and Recall from the Consortium to Establish a Registry for Alzheimer's Disease (CERAD) battery was applied to assess memory; a score < 5 was defined as impairment, in line with age-adjusted normative data $[35,36]$.

\section{Data collection}

Baseline characteristics were retrieved from participants, their caregivers and medical records. Stroke diagnosis and NIHSS scores were assessed by stroke physicians during hospital stay. At three-month follow-up, participants were evaluated at a hospital outpatient clinic. Motor and cognitive assessments were performed by healthcare personnel who were trained to perform these tests and according to a standardized manual.

\section{Statistics}

Demographic and clinical characteristics were summarized using mean and SD for continuous variables and frequencies and percentages for categorical variables. For analyses of prevalence, the clinical variables were dichotomized based on predefined cut-offs and investigated with cross tabulations between each of the motor and cognitive tests. Associations were studied using linear regression with the continuous variables of the cognitive tests as dependent variables and the motor measures as independent variables. First, regression analyses were performed for each combination of motor and cognitive assessments. Second, we conducted analyses for each of the cognitive tests one at a time, including all three motor assessments, as independent 
variables. All regression analyses were adjusted for age, sex, education and baseline NIHSS score, which had been pre-defined as plausible confounders. Residuals were checked for normality by visual inspection of Q-Q plots. Statistical significance was defined as two-sided $p$ value $<0.05$, and $95 \%$ confidence intervals $(\mathrm{CI})$ are reported where relevant. Data were analyzed using IBM SPSS Statistics for Windows, version 25 (IBM Corp., Armonk, NY, USA).

\section{Results}

\section{Baseline characteristics}

Of 815 patients recruited to the Nor-COAST study, 700 were followed up at 3 months, and of these, 567 completed at least one motor and one cognitive assessment (Fig. 1). The mean (SD) age of the study participants was 72.2 (11.7) years; 242 (43\%) were women; and 460 (82\%) were diagnosed with ischemic stroke. Baseline mean (SD) NIHSS score was 3.7 (4.7), and 416 (75\%) of the participants had NIHSS scores $\leq 4$ points, indicating minor strokes (Table 1). The pre-stroke modified Rankin Scale (mRS) score was $\leq 2$ in $533(94 \%)$ of the participants, and after 3 months, 475 (84\%) had an mRS score $\leq 2$ (Table 1 ). As compared to study participants, those lost to follow-up were significantly older (mean [SD] age 78.5 [10.6], $p$-value < 0.001) and had suffered more severe strokes (mean [SD] NIHSS score 6.9 [7.8], $p$-value $<0.001$ ), but there were no differences in sex.

\section{Prevalence of motor and cognitive impairments}

Scores for the motor and cognitive tests are presented in Table 2. SPPB scores $<10$ points were found in 210
(37\%) participants, indicating reduced mobility. DTC $\geq$ 20\% was measured in 146 (29\%) participants, indicating a clinically relevant reduction in dual task capacity, while grip strength was below cut-off in $97(45 \%)$ of the women and 120 (39\%) of the men, indicating a clinically relevant reduction of strength. On the cognitive tests, 185 (33\%) scored below 24 points on the MoCA, indicating reduced global cognition; TMT-B $>167 \mathrm{~s}$ indicated impaired executive function in 194 (37\%); and 10WLR score below five showed impairment in memory in 188 (39\%) of the participants.

Regarding the prevalence of concurrent impairment, dual-task cost in combination with each of the cognitive tests showed a prevalence of approximately $10 \%$ (range 9.5-11.3\%). The other combinations of tests resulted in reduced scores for both the cognitive and motor tests in about one-fifth of the participants (range 18.6-22.9\%) (Fig. 2). Of the participants who scored below 24 points on the MoCA, 103 (57\%) scored below 10 points on the SPPB, and of those who took more than $167 \mathrm{~s}$ to complete the TMT-B or could not complete it, 102 (54\%) scored below 10 points on the SPPB (Fig. 2).

\section{Associations between motor and cognitive function}

As shown in Table 3, the regression analyses showed that both the SPPB score and grip strength were associated with scores on the MoCA $(p<0.001)$, TMT-B $(p<$ $0.001)$ and 10WLR $(p=0.001)$. For example, the estimated regression coefficient $\mathrm{B}=0.465$ for SPPB with MoCA as dependent variable means that for two individuals with the same age, sex, education and stroke severity (NIHSS score at admission), and with one score

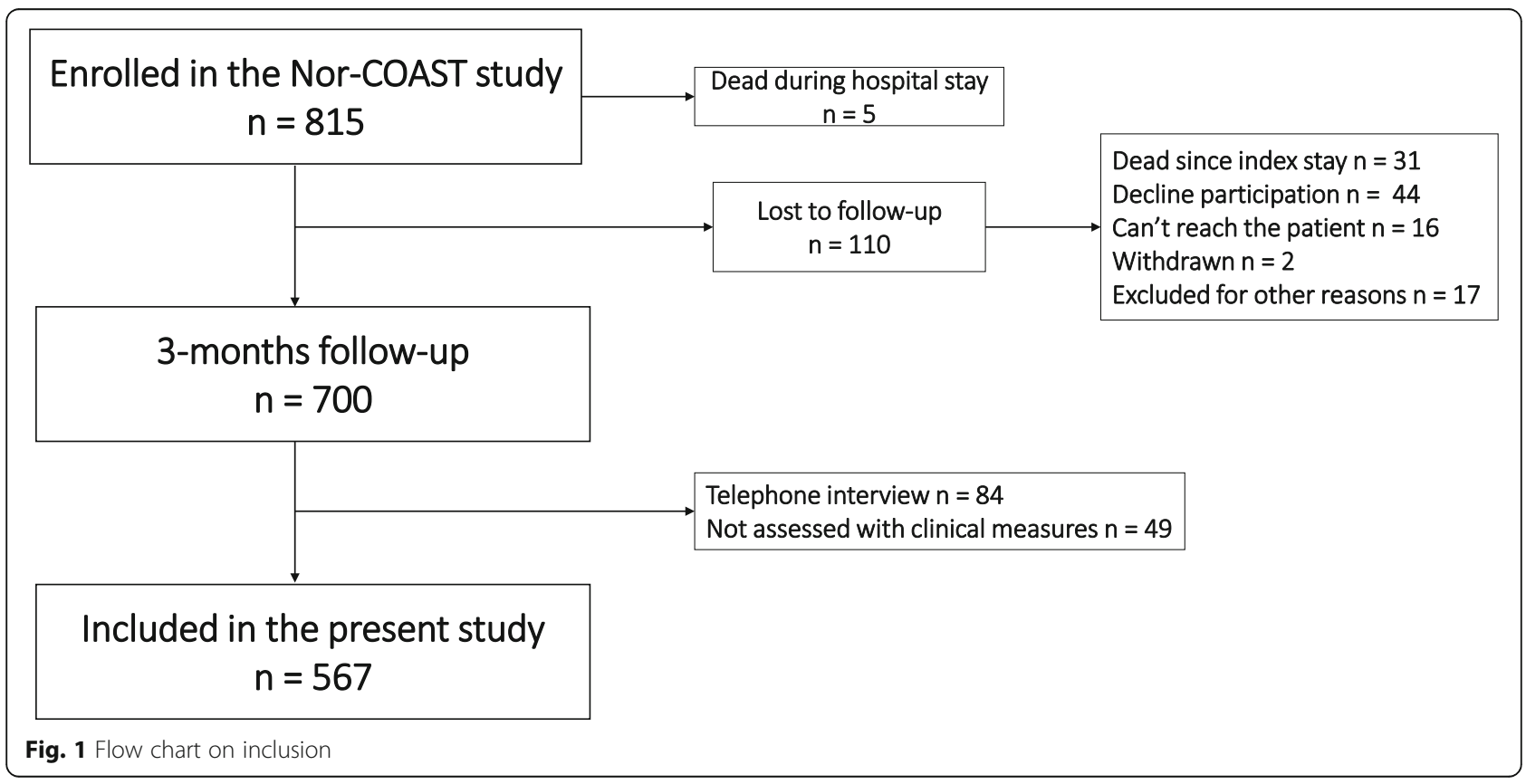


Table 1 Baseline characteristics

\begin{tabular}{|c|c|c|c|}
\hline & $\mathrm{n}$ & & \\
\hline \multicolumn{4}{|l|}{ Demographics } \\
\hline Age, years, mean (SD) & 567 & 72.2 & $(11.7)$ \\
\hline Females, n (\%) & 567 & 242 & $(42.7 \%)$ \\
\hline Living alone, n (\%) & 564 & 195 & $(34.4 \%)$ \\
\hline Education > 9 years, $\mathrm{n}(\%)$ & 567 & 424 & $(74.8 \%)$ \\
\hline \multicolumn{4}{|l|}{ Stroke classification } \\
\hline Infarction, n (\%) & 558 & 460 & $(82.4)$ \\
\hline Haemorrhage, n (\%) & 558 & 51 & $(9.0 \%)$ \\
\hline Not classified, n (\%) & 558 & 47 & $(8.3 \%)$ \\
\hline NIHSS score at admittance (0-42), mean (SD) & 553 & 3.7 & $(4.7)$ \\
\hline \multicolumn{4}{|l|}{ NIHSS score at admittance } \\
\hline Mild stroke (0-4), n (\%) & 553 & 416 & $(75.2 \%)$ \\
\hline Moderate stroke (5-15), n (\%) & 553 & 113 & $(20.4 \%)$ \\
\hline Moderate to severe stroke (16-20), n (\%) & 553 & 20 & $(3.5 \%)$ \\
\hline Severe stroke (> 20), n (\%) & 553 & 4 & $(0.7 \%)$ \\
\hline Charlson Comorbidity Index, baseline (0-24), mean (SD) & 567 & 3.9 & $(1.9)$ \\
\hline Antiplatelet treatment at discharge, $\mathrm{n}(\%)$ & 567 & 388 & $(68.4 \%)$ \\
\hline Anticoagulation treatment at discharge, $\mathrm{n}(\%)$ & 567 & 166 & $(29.3 \%)$ \\
\hline mRS (0-6), pre-stroke, mean (SD) & 565 & 0.7 & $(0.9)$ \\
\hline
\end{tabular}

SD standard deviation, NIHSS National Institutes of Health Stroke Scale, (0-42p), mRS Modified Rankin Scale (0-6p)

difference in SPPB, the expected difference in MOCA is 0.465 . The DTC was associated only with the score on the TMT-B $(p=0.005)$. These associations remained sta-

Table 2 Assessments at three-month follow-up

\begin{tabular}{|c|c|c|c|}
\hline & $\mathrm{n}$ & & \\
\hline \multicolumn{4}{|l|}{ Assessments of motor performance } \\
\hline SPPB (0-12), mean (SD) & 563 & 9.4 & $(3.1)$ \\
\hline Dual-task cost, (\%), mean (SD) & 500 & 12.3 & $(16.2)$ \\
\hline \multicolumn{4}{|l|}{ Grip strength (kg), mean (SD) } \\
\hline Men & 305 & 40.1 & $(11.7)$ \\
\hline Women & 216 & 21.7 & $(6.9)$ \\
\hline Gait speed 4 m, (m/s), mean (SD) & 550 & 1.0 & $(0.3)$ \\
\hline \multicolumn{4}{|l|}{ Assessments of cognitive performance } \\
\hline MoCA (0-30), mean (SD) & 562 & 23.8 & $(4.7)$ \\
\hline TMT-B (0-300), mean (SD) & 525 & 154.7 & $(83.9)$ \\
\hline 10-Word List Recall (0-10), mean (SD) & 484 & 5.2 & $(2.7)$ \\
\hline \multicolumn{4}{|l|}{ Assessments of function } \\
\hline Able to walk 200 m, 3 months, n (\%) & 527 & 485 & $(92.0 \%)$ \\
\hline mRS (0-6), 3 months, mean (SD) & 565 & 2.0 & $(1.3)$ \\
\hline Nottingham EADL (0-66), 3 months, mean (SD) & 553 & 49.0 & $(13.0)$ \\
\hline \multicolumn{4}{|c|}{$\begin{array}{l}\text { SD standard deviation, SPPB Short Physical Performance Battery (0-12p), Dual- } \\
\text { task cost ([single-task gait speed - dual-task gait speed]/single-task gait speed } \\
\times 100)(0-100 \%), \text { MoCA Montreal Cognitive Assessment (0-30p), TMT-B Trail } \\
\text { Making Test Part B (0-300 s), 10-Word List Recall the recall part of the 10-Word } \\
\text { List Learning and Recall from the CERAD (Consortium to Establish a Registry } \\
\text { for Alzheimer's Disease) Battery (0-10 words), mRS Modified Rankin Scale, } \\
\text { Nottingham EADL Nottingham Extended Activities of Daily Living scale (0-66p) }\end{array}$} \\
\hline
\end{tabular}
tistically significant in the adjusted model (Table 4).

\section{Discussion}

In this cross-sectional study of survivors who had suffered mainly mild strokes, we found impairments in either cognitive function or motor function in about onethird of patients, while the prevalence of concurrent impairment ranged from 10 to $23 \%$, depending on which combination of motor and cognitive domains were assessed. Impairments in mobility and grip strength were associated with impaired global cognition, executive dysfunction and impaired memory. Higher dual-task cost was associated only with executive dysfunction. The identification of concurrent impairments could be relevant for preventing functional decline and should encourage a holistic approach to this patient group.

The scores on post-stroke cognitive tests identifying impairment shown here are in line with the results of previous studies [37]. A trend of reduced mobility 3 months post-stroke, especially in patients having suffered from moderate stroke, has been described [38], and Vahlberg et al. [39] found SPPB scores in line with finding from the present study, which are lower than reported in the general population [40]. Motor function has been reported to be a significant predictor of 


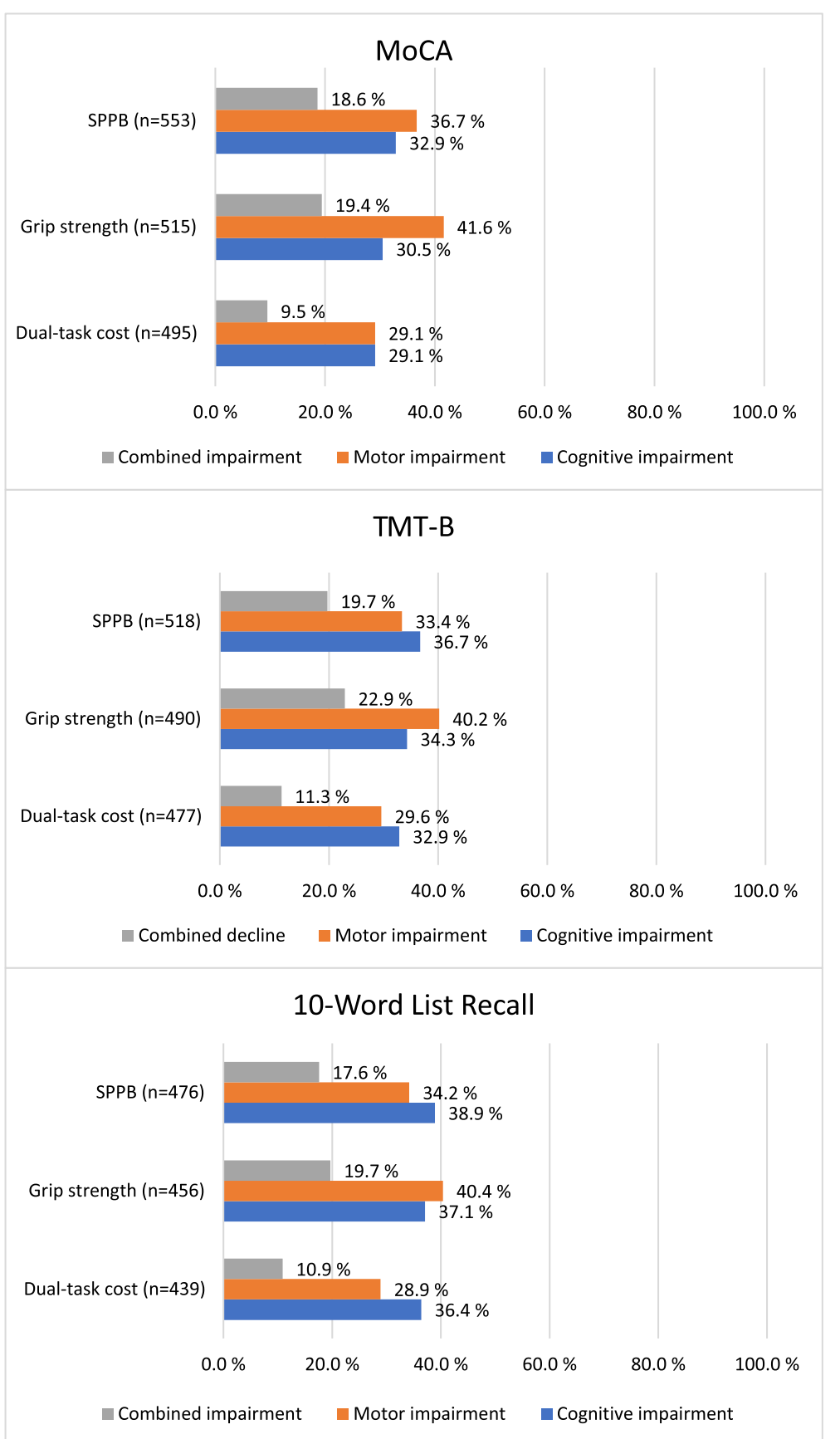

Fig. 2 Prevalence of motor and cognitive impairments. MoCA Montreal Cognitive Assessment; SPPB Short Physical Performance battery; Dual-task cost ([single-task gait speed - dual-task gait speed]/single-task gait speed $\times 100$ ); TMT-B Trail Making Test Part B. Impaired performance was defined as: MoCA $<24$ p, TMT-B $>167$ s, 10-Word List Recall $<5$ words, SPPB $<10$ p, Dual-task cost $>20 \%$ and grip strength $<21 \mathrm{~kg}$ (women) and $<37 \mathrm{~kg}$ (men)

cognitive decline after stroke [12]. However, associations between motor performance and cognitive domains have not, to the best of our knowledge, been examined previously in stroke samples. The dual-task cost has been recommended as a valid measure of the motor-cognitive interphase [41] and found to predict incident dementia in individuals with mild cognitive impairment without previous history of stroke [16]. Several studies of elderly persons with cognitive impairment have shown a strong association between the dual-task test and global cognition [10, 19], but this was not supported by a study of patients with Parkinson's disease [42]. In the present study, dual-task cost was associated only with executive function. 
Table 3 Regression analyses with one motor domain at a time as covariate ${ }^{\text {a }}$

\begin{tabular}{|c|c|c|c|c|}
\hline & \multicolumn{4}{|c|}{ Regression coefficient } \\
\hline & $\bar{n}$ & $B$ & $p$-value & $95 \% \mathrm{Cl}$ \\
\hline \multicolumn{5}{|l|}{ MoCA } \\
\hline SPPB & 539 & 0.465 & $<0.001$ & $0.352,0.578$ \\
\hline Dual-task cost & 485 & -0.004 & 0.661 & $-0.023,0.015$ \\
\hline Grip strength & 503 & 0.075 & $<0.001$ & $0.039,0.112$ \\
\hline \multicolumn{5}{|l|}{ TMT-B } \\
\hline SPPB & 507 & -9.494 & $<0.001$ & $-11.726,-7.925$ \\
\hline Dual-task cost & 468 & 0.475 & 0.005 & $0.075,0.875$ \\
\hline Grip strength & 479 & -1.972 & $<0.001$ & $-2.672,-1.272$ \\
\hline \multicolumn{5}{|c|}{ 10-Word List Recall } \\
\hline SPPB & 464 & 0.132 & 0.001 & $0.054,0.211$ \\
\hline Dual-task cost & 430 & 0.000 & 0.951 & $-0.014,0.015$ \\
\hline Grip strength & 446 & 0.041 & 0.001 & $0.016,0.066$ \\
\hline
\end{tabular}

MoCA Montreal Cognitive Assessment, SPPB Short Physical Performance Battery, Dual-task cost ([single-task gait speed - dual-task gait speed]/singletask gait speed $\times 100)$, TMT-B Trail Making Test Part B

adjusted for age, sex, education and stroke severity (NIHSS score at admission)

In the present study, we have demonstrated that, although the patients suffered mainly mild strokes with low NIHSS scores, cognitive and motor impairments as well as concurrent impairments are prevalent, as the majority of patients with impaired MoCA scores also had impaired SPPB scores and vice versa. Concurrent motor and cognitive impairments have been shown to predict poor prognosis as, for example, an increased risk of

Table 4 Regression analyses with all motor domains as covariates in the same model $^{a}$

\begin{tabular}{llll}
\hline & \multicolumn{3}{l}{ Regression coefficient } \\
\cline { 2 - 4 } & $\mathbf{B}$ & $\boldsymbol{p}$-value & $\mathbf{9 5 \% ~ C l}$ \\
\hline MoCA $(n=463)$ & & & \\
SPPB & 0.309 & $<0.001$ & $0.179,0.438$ \\
Dual-task cost & -0.006 & 0.497 & $-0.025,0.012$ \\
Grip strength & 0.063 & $<0.001$ & $0.028,0.097$ \\
TMT-B ( $n=448)$ & & & \\
SPPB & -8.588 & $<0.001$ & $-11.204,-5.972$ \\
Dual-task cost & 0.499 & 0.009 & $0.124,0.873$ \\
Grip strength & -1.613 & $<0.001$ & $-2.296,-0.930$ \\
10-Word List Recall $(n=417)$ & & \\
SPPB & 0.099 & 0.048 & $0.001,0.198$ \\
Dual-task cost & -0.002 & 0.786 & $-0.017,0.013$ \\
Grip strength & 0.036 & 0.010 & $0.010,0.061$ \\
\hline
\end{tabular}

MoCA Montreal Cognitive Assessment, SPPB Short Physical Performance Battery, Dual-task cost ([single-task gait speed - dual-task gait speed]/singletask gait speed $\times 100$ ), TMT-B Trail Making Test Part B

adjusted for age, sex, education and stroke severity (NIHSS score at admission) developing dementia in stroke-free populations [43, 44], and there is reason to believe that these impairments can impact recovery and everyday life [45]. Therefore, we believe that, as part of the routine follow-up protocol after stroke, assessments of cognition and global motor functions should be performed to gain more information that may be relevant for prognosis and may indicate a need for continued rehabilitation even 3 months after a stroke [45]. Further cognitive function is very important for planning and performing rehabilitation and cognitive impairment, such as impaired memory or executive dysfunction, might change responsiveness to motor rehabilitation, which should be taken into consideration when developing targeted interventions in stroke populations [46]. We did not find support for motor performance being more closely associated with specific cognitive domains, and we suggest using global tests like MoCA and SPPB in order to assess cognitive and motor function.

Shared underlying pathologies might explain concurrent impairment in cognition and motor performance, for which there is increasing evidence [9]. Theoretically, the impairments can be caused directly by the stroke lesion or by structural and functional impairments that appear at a distance from the stroke lesion, also known as diaschisis [47]. Previous studies have shown that stroke survivors have small-vessel disease and neurodegeneration in addition to focal stroke lesions [48, 49], and small-vessel disease and neurodegenerative disease are both reported to be associated with impairments in gait and balance as well as cognition $[8,50-52]$. Consequently, the observed impairments in motor and cognitive functions may be a symptom of both focal and disseminated brain pathology. The lack of findings of distinct associations could support a hypothesis of mixed pathology, but further research, including neuroimaging, is needed to achieve better insight.

The strengths of this work are the multicentre design, a relatively large sample size, and the comprehensive test battery that has been performed in line with consensus guidelines [7]. It is also a strength that the Nor-COAST participants are shown to be representative of the majority of the Norwegian stroke population that suffers from mild strokes [53]. Compared to the Norwegian Stroke Registry, the participants included in this sub-study were slightly younger (72 vs 73 years) with a larger proportion suffering from minor impairments (75\% vs $69 \%)$ measured by baseline NIHSS scores [4]. Despite relatively wide inclusion criteria, there was a selection bias towards younger stroke patients with milder strokes. As a result, this sub-sample probably comprises those individuals most likely to benefit from interventions designed to prevent further functional decline and may be generalized to this part of the stroke population. The 
prevalence of impairments reported in this study is closely related to the choice of test battery and cut-off values, which are in line with current recommendations [7]. For MoCA, the cut-off for impairment was set at < 24 points, $[33,54]$ which should also detect patients with mild cognitive impairment in this population with elderly stroke patients. Because of the large scale of the study, we used a standardized protocol for dual-task cost with counting backwards. This could represent a methodological limitation in this heterogeneous sample, and individual adjustments such as applying more-complex cognitive tasks or motor performance tests could have resulted in other findings [55] but were deemed beyond the scope of this multicentre study. Lastly, the crosssectional design of the study limits any conclusions in regard to causality.

\section{Conclusion}

We found subtle cognitive and motor impairments and combinations of these to be relatively common among stroke survivors despite high premorbid functioning and minor strokes. Motor performance was associated with memory, executive function and global cognition. Our findings add knowledge about post-stroke motor and cognitive function and highlight the need for awareness of motor and cognitive impairments in stroke populations. Further research is needed in regard to the prognostic significance of our findings, as well as their associations to underlying pathology. Concurrent impairments should be recognized both in a short- and long-term perspective in order to identify and target those patients in need of prolonged rehabilitation to prevent further functional decline.

\section{Abbreviations}

10WLR: 10-Word List Recall; ADL: Activities of daily living; CERAD: Consortium to Establish a Registry for Alzheimer's Disease; DTC: Dual-task cost; MoCA: Montreal Cognitive Assessment; MRI: Magnetic Resonance Imaging; mRS: Modified Rankin Scale; NIHSS: National Institutes of Health Stroke Scale; Nor-COAST: Norwegian Cognitive Impairment After Stroke; SPPB: Short Physical Performance Battery; TMT-B: Trail Making Test Part B

\section{Acknowledgements}

We thank all participants and their families for their contributions, the NorCOAST research group and the dedicated study staff at St. Olavs hospital, Haukeland University Hospital, Ålesund Hospital, Vestre Viken Hospital Trust; Bærum Hospital and Oslo University Hospital; Ullevål for their valuable work with collection and preparation of data.

\section{Authors' contributions}

MSE, IS and PT have been responsible for planning the present report and have been the major contributors in writing the manuscript. MHU contributed to the planning of the study. SL has been involved in planning and interpretation of statistical analyses, which were performed by $S L$ and MSE. TA, RM-K, HI-H, ABK, MKB, HN, YMS and HE are members of the steering committee of the Nor-COAST study and have been involved in planning the design of the Nor-COAST study and in the recruitment and follow-up of participants in the present study. All authors have critically read and approved the final manuscript.

\section{Funding}

The Nor-COAST study is funded by the Norwegian Health Association, and additional funding was provided by the Department of Neuromedicine and Movement Science, Faculty of Medicine and Health Science, NTNUNorwegian University of Science and Technology.

\section{Availability of data and materials}

The datasets generated and analysed during the current study are not publicly available due to Norwegian legal regulations. Requests to obtain anonymized study data can be addressed to the corresponding author.

\section{Ethics approval and consent to participate}

The present study was carried out according to the Declaration of Helsinki, and participation was voluntary and based on written informed consent from the participant, or, in cases where participants were not able to give consent themselves, by their proxy. The study has been approved by the Regional Committee for Medical and Health Research Ethics in North, REK Nord (REC number 2015/171). ClinicalTrials.gov Identifier: NCT02650531.

\section{Consent for publication}

Not applicable.

\section{Competing interests}

$A B K$ and IS have been investigators in the drug trial Boehringer-Ingelheim 1346.0023, and ABK has also been an investigator for Roche BN29553. The remaining authors declare no conflicts interest.

\section{Author details}

'Department of Neuromedicine and Movement Science, Faculty of Medicine and Health Sciences, NTNU-Norwegian University of Science and Technology, Trondheim, Norway. ${ }^{2}$ Department of Geriatric Medicine, St. Olavs Hospital, Trondheim University Hospital, Trondheim, Norway. ${ }^{3}$ Department of Mental Health, Faculty of Medicine and Health Sciences, NTNU-Norwegian University of Science and Technology, Trondheim, Norway. ${ }^{4}$ Department of Medicine, Bærum Hospital, Vestre Viken Hospital Trust, Drammen, Norway. ${ }^{5}$ Department of Geriatric Medicine, Oslo University Hospital, Oslo, Norway. ${ }^{6}$ Department of Radiology and Nuclear Medicine, Oslo University Hospital, Oslo, Norway. IInstitute of Clinical Medicine, University of Oslo, Oslo, Norway. ${ }^{8}$ Department of Neurology, Haukeland University Hospital, Bergen, Norway. ${ }^{9}$ Centre for Age-Related Medicine, Stavanger University Hospital, Stavanger, Norway. ${ }^{10}$ Institute of Clinical Medicine, University of Bergen, Bergen, Norway. ${ }^{11}$ Medical Department, Ålesund Hospital, Møre and Romsdal Health Trust, Ålesund, Norway. ${ }^{12}$ Stroke Unit, Department of Internal Medicine, St. Olavs Hospital, Trondheim University Hospital, Trondheim, Norway.

Received: 2 December 2020 Accepted: 15 January 2021

Published online: 05 February 2021

\section{References}

1. Murray CJ, Vos T, Lozano R, Naghavi M, Flaxman AD, Michaud C, et al. Disability-adjusted life years (DALYs) for 291 diseases and injuries in 21 regions, 1990-2010: a systematic analysis for the global burden of disease study 2010. Lancet. 2012;380(9859):2197-223.

2. Kwakkel G, Kollen B, Twisk J. Impact of time on improvement of outcome after stroke. Stroke. 2006;37(9):2348-53.

3. Ullberg T, Zia E, Petersson J, Norrving B. Changes in functional outcome over the first year after stroke: an observational study from the Swedish stroke register. Stroke. 2015;46(2):389-94.

4. Fjæertoft H, Indredavik B, Mørch B, Phan A, Skogseth-Stephani R, Varmdal T. Årsrapport 2018, Norsk Hjerneslagregister; 2019.

5. Munthe-Kaas R, Aam S, Ihle-hansen H, Lydersen S, Knapskog A-B, Wyller T, et al. Impact of different methods defining post-stroke neurocognitive disorder: The Nor-COAST study. Alzheimers Dement. 2020;6(1):e12000e12000.

6. Sachdev PS, Brodaty H, Valenzuela MJ, Lorentz L, Looi JC, Berman K, et al. Clinical determinants of dementia and mild cognitive impairment following ischaemic stroke: the Sydney stroke study. Dement Geriatr Cogn Disord. 2006;21(5-6):275-83

7. Montero-Odasso M, Almeida QJ, Bherer L, Burhan AM, Camicioli R, Doyon J, et al. Consensus on shared measures of mobility and cognition: from the 
Canadian Consortium on Neurodegeneration in Aging (CCNA). J Gerontol A Biol Sci Med Sci. 2018;74(6):897-909.

8. Auriat AM, Ferris JK, Peters S, Ramirez J, Black SE, Jacova C, et al. The impact of covert lacunar infarcts and white matter Hyperintensities on cognitive and motor outcomes after stroke. J Stroke Cerebrovasc Dis. 2019;28(2):3818.

9. Chhetri JK, Chan P, Vellas B, Cesari M. Motoric cognitive risk syndrome: predictor of dementia and age-related negative outcomes. Front Med. 2017; 4:166

10. Verghese J, Annweiler C, Ayers E, Barzilai N, Beauchet O, Bennett DA, et al. Motoric cognitive risk syndrome: multicountry prevalence and dementia risk. Neurology. 2014;83(8):718-26.

11. Ursin MH, Bergland A, Fure B, Torstad A, Tveit A, Ihle-Hansen H. Balance and mobility as predictors of post-stroke cognitive impairment. Dement Geriatr Cogn Dis Extra. 2015;5(2):203-11.

12. Ben Assayag E, Shenhar-Tsarfaty S, Korczyn AD, Kliper E, Hallevi H, Shopin L, et al. Gait measures as predictors of poststroke cognitive function: evidence from the TABASCO study. Stroke. 2015;46(4):1077-83.

13. Verghese J, Lipton RB, Hall CB, Kuslansky G, Katz MJ, Buschke H. Abnormality of gait as a predictor of non-Alzheimer's dementia. N Engl J Med. 2002; 347(22):1761-8

14. Beauchet O, Sekhon H, Barden J, Liu-Ambrose T, Chester VL, Szturm T, et al. Association of Motoric Cognitive Risk Syndrome with cardiovascular disease and risk factors: results from an original study and meta-analysis. $J$ Alzheimers Dis. 2018;64(3):875-87.

15. Sagnier S, Renou P, Olindo S, Debruxelles S, Poli M, Rouanet F, et al. Gait change is associated with cognitive outcome after an acute ischemic stroke. Front Aging Neurosci. 2017;9:153.

16. Montero-Odasso MM, Sarquis-Adamson Y, Speechley M, Borrie MJ, Hachinski VC, Wells J, et al. Association of dual-task gait with incident dementia in mild cognitive impairment: results from the gait and brain study. JAMA Neurology. 2017;74(7):857-65.

17. Montero-Odasso M, Speechley M, Muir-Hunter SW, Sarquis-Adamson Y, Sposato LA, Hachinski V, et al. Motor and cognitive trajectories before dementia: results from gait and brain study. J Am Geriatr Soc. 2018;66(9): 1676-83.

18. Kueper JK, Speechley M, Lingum NR, Montero-Odasso M. Motor function and incident dementia: a systematic review and meta-analysis. Age Ageing. 2017:46(5):729-38.

19. Tangen GG, Engedal K, Bergland A, Moger TA, Mengshoel AM. Relationships between balance and cognition in patients with subjective cognitive impairment, mild cognitive impairment, and Alzheimer disease. Phys Ther. 2014;94(8):1123-34.

20. Shim H, Kim M, Won CW. Motoric cognitive risk syndrome is associated with processing speed and executive function, but not delayed free recall memory: the Korean frailty and aging cohort study (KFACS). Arch Gerontol Geriatr. 2020:87:103990.

21. Montero-Odasso M, Verghese J, Beauchet O, Hausdorff JM. Gait and cognition: a complementary approach to understanding brain function and the risk of falling. J Am Geriatr Soc. 2012;60(11):2127-36.

22. Reitan RM. Validity of the trail making test as an indicator of organic brain damage. Percept Mot Skills. 1958;8:271-6.

23. Nasreddine ZS, Phillips NA, Bedirian V, Charbonneau S, Whitehead V, Collin I, et al. The Montreal cognitive assessment, MoCA: a brief screening tool for mild cognitive impairment. J Am Geriatr Soc. 2005;53(4):695-9.

24. Thingstad P, Askim T, Beyer MK, Bråthen $\mathrm{G}$, Ellekjær $\mathrm{H}$, Ihle-Hansen $\mathrm{H}$, et al. The Norwegian cognitive impairment after stroke study (nor-COAST): study protocol of a multicentre, prospective cohort study. BMC Neurol. 2018;18(1): 193.

25. The World Health Organization MONICA Project (monitoring trends and determinants in cardiovascular disease): a major international collaboration. WHO MONICA Project Principal Investigators. J Clin Epidemiol. 1988;41(2): 105-14.

26. Brott T, Adams HP Jr, Olinger CP, Marle JR, Barsan WG, Biller J, et al. Measurements of acute cerebral infarction: a clinical examination scale. Stroke. 1989;20(7):864-70.

27. Gladman JR, Lincoln NB, Adams SA. Use of the extended ADL scale with stroke patients. Age Ageing. 1993;22(6):419-24.

28. van Swieten JC, Koudstaal PJ, Visser MC, Schouten HJ, van Gijn J. Interobserver agreement for the assessment of handicap in stroke patients. Stroke. 1988;19(5):604-7.
29. Charlson ME, Pompei P, Ales KL, MacKenzie CR. A new method of classifying prognostic comorbidity in longitudinal studies: development and validation. J Chronic Dis. 1987;40(5):373-83.

30. Guralnik JM, Simonsick EM, Ferrucci L, Glynn RJ, Berkman LF, Blazer DG, et al. A short physical performance battery assessing lower extremity function: association with self-reported disability and prediction of mortality and nursing home admission. J Gerontol. 1994;49(2):M85-94.

31. Guralnik JM, Ferrucci L, Simonsick EM, Salive ME, Wallace RB. Lowerextremity function in persons over the age of 70 years as a predictor of subsequent disability. N Engl J Med. 1995;332(9):556-61.

32. Sallinen J, Stenholm S, Rantanen T, Heliovaara M, Sainio P, Koskinen S. Hand-grip strength cut points to screen older persons at risk for mobility limitation. J Am Geriatr Soc. 2010:58(9):1721-6.

33. Borland E, Nägga K, Nilsson PM, Minthon L, Nilsson ED, Palmqvist S. The Montreal cognitive assessment: normative data from a large Swedish population-based cohort. J Alzheimers Dis. 2017;59(3):893-901.

34. Ivnik RJ, Malec JF, Smith GE, Tangalos EG, Petersen RC. Neuropsychological tests' norms above age 55: COWAT, BNT, MAE token, WRAT-R reading, AMNART, STROOP, TMT, and JLO. Clin Neuropsychol. 1996;10(3):262-78.

35. Welsh KA, Butters N, Mohs RC, Beekly D, Edland S, Fillenbaum G, et al. The consortium to establish a registry for Alzheimer's disease (CERAD). Part V. a normative study of the neuropsychological battery. Neurology. 1994;44(4): 609-14.

36. Morris JC, Heyman A, Mohs RC, Hughes JP, van Belle G, Fillenbaum G, et al. The consortium to establish a registry for Alzheimer's disease (CERAD). Part I. clinical and neuropsychological assessment of Alzheimer's disease. Neurology. 1989;39(9):1159-65.

37. Barbay M, Diouf M, Roussel M, Godefroy O. Systematic review and metaanalysis of prevalence in post-stroke neurocognitive disorders in hospitalbased studies. Dement Geriatr Cogn Disord. 2018;46(5-6):322-34.

38. Buvarp D, Rafsten L, Sunnerhagen KS. Predicting longitudinal progression in functional mobility after stroke: a prospective cohort study. Stroke. 2020 51(7):2179-87

39. Vahlberg B, Cederholm T, Lindmark B, Zetterberg L, Hellström K. Short-term and long-term effects of a progressive resistance and balance exercise program in individuals with chronic stroke: a randomized controlled trial. Disabil Rehabil. 2017;39(16):1615-22.

40. Bergland A, Strand BH. Norwegian reference values for the short physical performance battery (SPPB): the Tromsø study. BMC Geriatr. 2019;19(1):216.

41. Montero-Odasso M, Bergman H, Phillips NA, Wong CH, Sourial N, Chertkow H. Dual-tasking and gait in people with mild cognitive impairment. The effect of working memory. BMC Geriatr. 2009;9:41.

42. Gaßner H, Marxreiter F, Steib S, Kohl Z, Schlachetzki JCM, Adler W, et al. Gait and cognition in Parkinson's disease: cognitive impairment is inadequately reflected by gait performance during dual task. Front Neurol. 2017:8:550.

43. Montero-Odasso M, Speechley M, Muir-Hunter S, Pieruccini-Faria F, SarquisAdamson Y, Hachinski V, et al. Dual decline in gait speed and cognition is associated with future dementia: evidence for a phenotype. Age Ageing. 2020:49(6):995-1002.

44. Grande G, Vetrano DL, Fratiglioni L, Marseglia A, Vanacore N, Laukka EJ, et al. Disability trajectories and mortality in older adults with different cognitive and physical profiles. Aging Clin Exp Res. 2020;32(6):1007-16.

45. Wondergem R, Pisters MF, Wouters EJ, Olthof N, de Bie RA, Visser-Meily JMA, et al. The course of activities in daily living: who is at risk for decline after first ever stroke? Cerebrovasc Dis. 2017:43(1-2):1-8.

46. Lingo VanGilder J, Hooyman A, Peterson DS, Schaefer SY. Post-stroke cognitive impairments and responsiveness to motor rehabilitation: a review. Curr Phys Med Rehabil Rep. 2020;8(4):461-8.

47. Carrera E, Tononi G. Diaschisis: past, present, future. Brain. 2014;137(Pt 9): 2408-22.

48. Arba F, Quinn T, Hankey GJ, Ali M, Lees KR, Inzitari D. Cerebral small vessel disease, medial temporal lobe atrophy and cognitive status in patients with ischaemic stroke and transient ischaemic attack. Eur J Neurol. 2017;24(2): 276-82.

49. Georgakis MK, Duering M, Wardlaw JM, Dichgans M. WMH and long-term outcomes in ischemic stroke: a systematic review and meta-analysis. Neurology. 2019;92(12):e1298-e308.

50. Callisaya ML, Beare R, Phan T, Blizzard L, Thrift AG, Chen J, et al. Progression of white matter hyperintensities of presumed vascular origin increases the risk of falls in older people. J Gerontol A Biol Sci Med Sci. 2015;70(3):360-6. 
51. Molad J, Kliper E, Korczyn AD, Ben Assayag E, Ben Bashat D, ShenharTsarfaty S, et al. Only white matter Hyperintensities predicts post-stroke cognitive performances among cerebral small vessel disease markers: results from the TABASCO study. J Alzheimers Dis. 2017:56(4):1293-9.

52. Keleman A, Wisch JK, Bollinger RM, Grant EA, Benzinger TL, Morris JC, et al. Falls associate with neurodegenerative changes in ATN framework of Alzheimer's disease. J Alzheimers Dis. 2020;77:745-52.

53. Kuvås KRSI, Aam S, Thingstad P, Ellekjær H, Askim T. The risk of selection Bias in a clinical multi-center cohort study. Results from the Norwegian cognitive impairment after stroke (nor-COAST) study. Clin Epidemiol. 2020; 12:1327-36.

54. Shi D, Chen X, Li Z. Diagnostic test accuracy of the Montreal cognitive assessment in the detection of post-stroke cognitive impairment under different stages and cutoffs: a systematic review and meta-analysis. Neurol Sci. 2018:39(4):705-16.

55. Patel P, Bhatt T. Task matters: influence of different cognitive tasks on cognitive-motor interference during dual-task walking in chronic stroke survivors. Top Stroke Rehabil. 2014;21(4):347-57.

\section{Publisher's Note}

Springer Nature remains neutral with regard to jurisdictional claims in published maps and institutional affiliations.

Ready to submit your research? Choose BMC and benefit from:

- fast, convenient online submission

- thorough peer review by experienced researchers in your field

- rapid publication on acceptance

- support for research data, including large and complex data types

- gold Open Access which fosters wider collaboration and increased citations

- maximum visibility for your research: over $100 \mathrm{M}$ website views per year

At BMC, research is always in progress.

Learn more biomedcentral.com/submissions 